Modern Physics Letters A, Vol. 14, Nos. 8 \& 9 (1999) 629

(C) World Scientific Publishing Company

\author{
ERRATA
}

\title{
CONSTRAINTS OF MIXING ANGLES FROM LEPTON NUMBER VIOLATING PROCESSES
}

\author{
[Mod. Phys. Lett. A, Vol. 14, No. 6 (1999) 433-445]
}

H. Nishiura, K. Matsuda and T. Fukuyama

On p. 435 ,

(a) third line after Eq. (7),

instead of $400 \mathrm{GeV}$, it should read $400 \mathrm{MeV}$,

(b) fourth line after Eq. (7),

instead of $S=-1$, it should read $S=-3$. 